\title{
CARACTERIZAÇÃO OCEANOGRÁFICA E BIOGEOQUÍMICA DOS ESTUÁRIOS DOS RIOS TAVARES E DEFUNTOS, RESERVA EXTRATIVISTA DE PIRAJUBAÉ, FLORIANÓPOLIS, SC
}

\author{
SCHETTINI, C.A.F.; PEREIRA Fo., J. \& L. SPILLERE \\ CTTMar/UNIVALI - Cx.P. 360 - Itajaí, SC, 88302-202
}

\begin{abstract}
RESUMO
Este artigo apresenta uma caracterização preliminar das condições oceanográficas e biogeoquímicas dos estuários dos rios Tavares (ERT) e Defuntos (ERD), localizados no Saco dos Limões, Reserva Extrativista de Pirajubaé, Florianópolis, SC. Nos dias 30 de junho e 1 de julho de 2000 foram realizadas campanhas de coleta de dados em cada estuário durante ciclos completos de maré, 13 horas, sob condição de maré de sizígia. Nestas campanhas foram monitorados: velocidade e direção de corrente, salinidade, temperatura, material particulado em suspensão (MPS), pH e oxigênio dissolvido, e concentração de nutrientes inorgânicos dissolvidos (amônio, nitrito, nitrato, fosfato e silício). Apesar de estarem distantes menos de $1 \mathrm{~km}$, os estuários apresentaram significativas diferenças na variação intramareal dos parâmetros amostrados. Os parâmetros observados no ERT apresentaram maior coerência com as fases de enchente e vazante de maré, ao passo que no ERD as variações apresentaram padrões mais complexos. Em termos de transporte residual, observou-se que o ERT exporta sedimentos e nutrientes para o Saco dos Limões enquanto o ERD importa sedimentos, porém exporta nutrientes. Além da influência principal da maré astronômica semi-diurna sobre os estuários, seiches também desempenham papel importante, apresentando estes períodos entre 1 e 2 horas.
\end{abstract}

Palavras-chave: estuários, Santa Catarina, Florianópolis, Pirajubaé, Rio Tavares, Rio dos Defuntos.

\section{OCEANOGRAPHIC AND BIOGEOCHEMICAL CHARACTERIZATION OF TAVARES AND DEFUNTOS RIVERS ESTUARIES, PIRAJUBAÉ EXTRACTIVIST RESERVE, FLORIANÓPOLIS, SC}

\begin{abstract}
This paper presents a preliminary assessment on the oceanographic and biogeochemical characteristics of the Tavares River (ERT) and Defuntos River (ERD) estuaries, located in the Limões Bight, Pirajubaé Extractivist Reserve, Florianópolis, SC. Field surveys were carried out in the estuaries at June $30^{\text {th }}$ on July $1^{\text {st }}, 2000$, along complete tidal cycles, 13 hours, under spring tide condition. At every survey the follow parameters were monitored: current speed and direction, salinity, temperature, particulate suspended matter (PSM), pH, dissolved oxygen, and inorganic dissolved nutrients concentration (ammonium, nitrite, nitrate, phosphate and silicon). In spite of being close one another less than $1 \mathrm{~km}$, the estuaries showed considerably differences in the intra-tidal variation of the monitored parameters. The parameters in the ERT showed good coherence with flood and ebb tidal phases, meanwhile in the ERD they showed more complex pattern. In terms of net transport, the ERT exports PSM and nutrients towards Limões bight, and the ERD imports PSM though exports nutrients. Beside the major influence of the astronomical semi-diurnal tide, seiches are also important to these estuaries. The main seiches periods ranged between 1 and 2 hours.
\end{abstract}

Keywords: estuaries, Santa Catarina, Florianópolis, Pirajubaé, Tavares River, Defuntos River. 


\section{INTRODUÇÃO}

Estuários são ambientes aquáticos costeiros onde ocorre a diluição mensurável da água marinha pela água doce proveniente da drenagem continental, tendo uma livre conexão com o mar aberto (Cameron \& Pritchard, 1963), com seu limite continental determinado pelo limite superior da penetração da onda de maré (Fairbridge, 1980), sustentando espécies biológicas eurihalinas pelo menos em parte de seu ciclo de vida (Perillo, 1995). Estes ambientes apresentam grande diversidade fisiográfica, bem como grande diversidade de padrões de mistura e condições hidrodinâmicas. A geomorfologia destes ambientes associada com os regimes de maré e de descarga fluvial geram padrões de circulação distintos para cada estuário, podendo estes atuar como filtros ou como exportadores de matéria para a zona costeira adjacente (Shubel \& Kennedy, 1984). Alterações dos condicionantes da circulação estuarina podem acarretar mudanças no comportamento de um determinado estuário em relação ao balanço de massa de quantidades escalares.

Decorrente da concentração do desenvolvimento humano nas zonas costeiras, estuários são ambientes onde é comum observar impactos ambientais de diversas naturezas. Estes impactos variam desde o lançamento de efluentes domésticos, agrícolas ou industriais, até a alteração da morfologia da bacia estuarina para que esta se adeqüe às necessidades humanas, tais como dragagens, aterros e retificações de canais. O sistema estuarino das baías Norte e Sul em Florianópolis (Figura 1) é um caso típico de impactos ambientais gerados pelo crescimento urbano. Diversos pequenos estuários fluem para as baías, sendo que por apresentarem dimensões reduzidas recebem pouca ou nenhuma atenção no que se refere a conservação ambiental. Muitas vezes estes ambientes são simplesmente canalizados e sua vegetação marginal derrubada para fins de urbanização.
Em 1998 foi iniciada a obra de aterro hidráulico da Baía Sul para a implementação da Via Expressa Sul, o qual alterou significativamente a morfologia do Saco dos Limões em toda sua orla leste. Na região sul do saco está localizada a Reserva Extrativista de Pirajubaé, que inclui uma região de baixios e manguezal. Cruzando o maguezal há alguns estuários, sendo o maior o estuário do Rio Tavares, que mais ou menos delimita o início do manguezal à leste. Os outros estuários são menores e bastante parecidos entre si. O presente trabalho objetiva fornecer uma caracterização oceanográfica dos estuários do Rio Tavares e do Rio dos Defuntos, sendo este último representativo dos demais estuários.

\section{MATERIAL E MÉTODOS}

Este trabalho é baseado em dados físicos e biogeoquímicos amostrados próximos da desembocadura nos estuários dos rios Tavares (ERT) e dos Defuntos (ERD; Figura 1), em campanhas de coleta em dias sucessivos abrangendo um ciclo completo de maré cada (13 horas). As campanhas foram realizadas nos dias 30 de junho e 1 de julho de 2000 sob condição de maré de sizígia. No estuário do Rio Tavares a campanha iniciou às 8 e encerrou às 20 horas, e no estuário do Rio dos Defuntos, iniciou às 9 e encerrou às 21 horas. Durante estas campanhas foram coletadas informações in situ de nível da água, velocidade e direção de correntes, salinidade, temperatura, material particulado em suspensão (MPS), oxigênio dissolvido e $\mathrm{pH}$. Amostras de água foram coletadas para posterior análise em laboratório da concentração de nutrientes inorgânicos dissolvidos.

Dados de nível da água foram coletados a cada 10 minutos com um marégrafo de pressão RichardBranckerTM TG-205, instalado no pier da Marina Veleiros da Ilha, no limite norteoeste do Saco dos Limões (Figura 1). Os dados de nível de água foram coletados continuamente a partir das 8:00 horas do dia 30 até às 
23:50 do dia 31. A Figura 2 apresenta a variação do nível da água durante os dias 30 de junho e 1 de julho, com o período de amostragem em cada estuário em negrito. Em função da falta de referência de nível, os dados foram referenciados ao nível médio de cada dia de amostragem. Dados de velocidade e direção de corrente foram obtidos com fundeio de um correntógrafo acústico Falmouth ${ }^{\mathrm{TM}}$ 3D$A C M($ próximo à desembocadura nos estuários. O correntógrafo aquisitou dados à $0,5 \mathrm{~m}$ abaixo da supefície, com médias de 2 minutos com taxas de aquisição de $5,5 \mathrm{~Hz}$. O correntógrafo aquisitou também dados de temperatura e turbidez com um turbidímetro de retroespalhamento ótico SeaPoint ${ }^{\mathrm{TM}}$. O turbidímetro foi calibrado para conversão do sinal para MPS para o estuário do Rio Itajaí-açu (Schettini \& D'Aquino, 1998), e os valores obtidos foram interpretados como aproximação na falta de uma curva específica para estes estuários.

No estuário do Rio Tavares a salinidade foi obtida em perfis verticais a cada hora com uma sonda tipo CTD SensorDataTM SD202 pró- ximo ao local do fundeio do correntógrafo. No estuário do Rio dos Defuntos o CTD ficou fixo na estrutura de proteção do correntógrafo, aquisitando dados à cada 10 minutos. Concentração de oxigênio dissolvido e $\mathrm{pH}$ foram coletados a cada hora com uma sonda multiparâmetro Horiba ${ }^{\mathrm{TM}}$ U10. Amostras de água de superfície foram coletadas para determinação de nutrientes inorgânicos dissolvidos em laboratório. Logo após a coleta, as amostras de água foram filtradas com filtros Whatman ${ } \mathrm{GF} / \mathrm{F}$, divididas em alíquotas e congeladas para posterior análise. Foram determinadas as concentrações de amônio $\left(\mathrm{NH}_{4}^{+}\right)$, nitrito mais nitrato $\left(\mathrm{NO}_{2}^{-}+\mathrm{NO}_{3}{ }^{-}\right)$, os quais somados fornecem o nitrogênio inorgânico dissolvido (NID), fosfato $\left(\mathrm{PO}_{4}^{3-}\right.$ ) e silício (Si). Para as determinações foram utilizados métodos colorimétricos clássicos adaptados de Strickland \& Parsons (1972).

Em função da descida da maré e da presença do plano intermareal que impossibilitou o acesso ao ponto de amostragem no ERD, as coletas de amostras de água e de parâmetros coletados com a sonda multiparâmetro Horiba

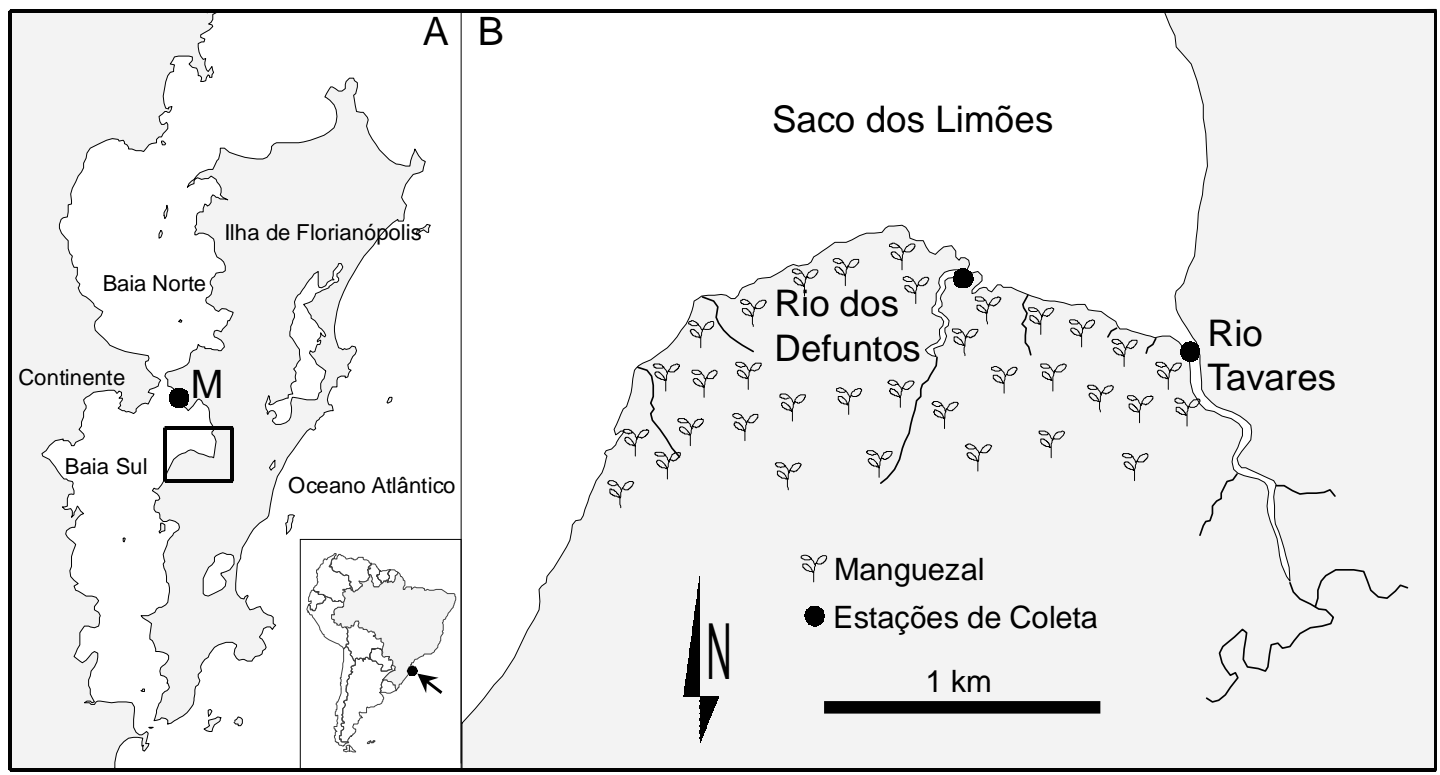

Figura 1: Localização dos estuários do Rio Tavares e do Rio dos Defundos. Em A, o ponto indicado com "M" é o local onde foi instalado o marégrafo. Em B, os pontos indicam as estações de amostragem. 
cessaram às 18 horas, porém o correntógrafo e o ctd permaneceram até o dia seguinte.

Os dados de velocidade e direção de corrente foram reduzidos para fornecer a velocidade longitudinal ao canal, convencionando que valores positivos representam correntes para montante, e valores negativos para jusante. Os dados de corrente foram posteriormente reduzidos para valores horários com médias de 10 minutos a partir de cada hora cheia. Estes valores foram utilizados para estimar o transporte de MPS e nutrientes dissolvidos pelo produto simples, fornecendo o transporte em quilogramas por metro quadrado de seção transversal. O transporte residual foi obtido pela promediação temporal de todos os valores. Os dados de nível de água foram analisados espectralmente para identificar as principais períodos de oscilação presentes no sinal. Foi utilizada a rotina padrão do aplicativo MATLAB ${ }^{\circledR}$ (MathWorks Inc. ${ }^{\top M}$ ) 'spectrum', a qual utiliza o periodograma promediado de Welch e janela móvel Hanning de 256 pontos, após a remoção de tendência da série.

\section{RESULTADOS}

Os resultados das campanhas de coleta de dados oceanográficos nos ERT e ERD estão sumariados nas Tabelas 1 e 2 em termos de média, desvio padrão, máximo e mínimo, com o transporte residual para um ciclo de maré para o MPS e nutrientes inorgânicos dissolvidos. As Figuras 3 e 4 apresentam as variações temporais de nível de água, velocidade de corrente longitudinal, salinidade, temperatura e MPS, e OD, $\mathrm{pH}, \mathrm{NH}_{4}{ }^{+}, \mathrm{NO}_{2}{ }^{-}+\mathrm{NO}_{3}{ }_{3}$, NID, $\mathrm{PO}_{4}{ }^{3-}$ e silício, respectivamente, para $\mathrm{O}$ estuário do Rio Tavares (ERT). As Figuras $6 \mathrm{e}$ 7 apresentam os mesmos parâmetros para o estuário do Rio dos Defuntos (ERD).

\section{Nível da água}

A variação de maré foi de 1,14 e 1,21 m nos dias 30 de junho e 1 de julho de 2000, respectivamente, sendo representativos de condições extremas de sizígia. A baixamar no dia 30 ocorreu às $9: 00$, com preamar às 14:30, $\mathrm{e}$ nova baixamar às 20:00 (Figura 4A). No dia 31 a primeira baixamar ocorreu às $9: 40$, com preamar próxima às 15:00, e com a segunda baixamar às 21:00 (Figura 5A). Em ambos os dias a segunda preamar foi $0,30 \mathrm{~m}$ acima da primeira, em função da natureza mista da maré semi-diurna regional (Schettini et al., 1996). A variação da maré apresentou-se bastante simétrica entre enchente e vazante.

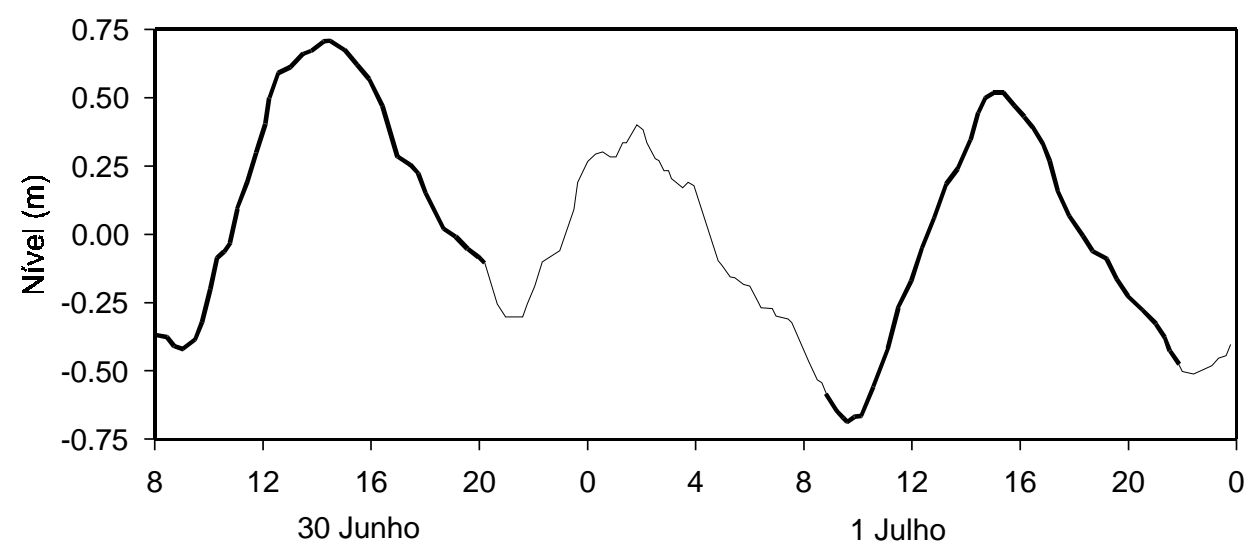

Figura 2: Variação do nível da água nos dias 30 de junho e 1 de julho, com resolução temporal de 10 minutos. Os períodos onde a linha está em negrito representam os períodos de coleta de dados, sendo o primeiro no estuário do Rio Tavares e o segundo no estuário do Rio dos Defuntos. 
Tabela 1: Sumário dos parâmetros medidos e analisados do estuário do Rio Tavares. V.C.: velocidade de corrente (média de 10 minutos para cada hora cheia); MPS: material particulado em suspensão; O.D.: oxigênio dissolvido; $\mathrm{NH}_{4}{ }^{+}$: amônia; $\mathrm{NO}_{2}{ }^{-}+\mathrm{NO}_{3} \cdot$ : nitrato e nitrito; $\mathrm{NID}$ : nitrogênio inorgânico dissolvido; $\mathrm{PO}_{4}{ }^{3-}$ : fosfato; Si: silício; D.P.: desvio padrão; T.R.: transporte residual (negativo significa saída, e positivo entrada, e o mesmo vale para a velocidade).

\begin{tabular}{|c|c|c|c|c|}
\hline Parâmetro & Média e D.P. & Mínimo & Máximo & $\begin{array}{c}\text { T.R. } \\
\left(\mathrm{kg} \cdot \mathrm{m}^{-2} \cdot \text { ciclo }^{-1}\right)\end{array}$ \\
\hline V.C. $\left(m \cdot s^{-1}\right)$ & $-0,03 \pm 0,28$ & $-0,35$ & 0,37 & \\
\hline Salinidade (\%०) & $30,1 \pm 4,6$ & 20,0 & 34,8 & \\
\hline Temperatura $\left({ }^{\circ} \mathrm{C}\right)$ & $19,3 \pm 0,3$ & 18,8 & 19,8 & \\
\hline $\operatorname{MPS}\left(\mathrm{mg} . \mathrm{I}^{-1}\right)$ & $36 \pm 24$ & 11 & 111 & -11 \\
\hline O.D. (mg. I $^{-1}$ ) & $7,9 \pm 1,6$ & 5,4 & 9,6 & \\
\hline $\mathrm{pH}$ & $7,6 \pm 0,3$ & 7,2 & 8,0 & \\
\hline $\mathrm{NH}_{4}^{+}(\mu \mathrm{Mol})$ & $14,6 \pm 9,2$ & 4,6 & 35,5 & $-41,2 \times 10^{-3}$ \\
\hline $\mathrm{NO}_{2}^{-}+\mathrm{NO}_{3}^{-}(\mu \mathrm{Mol})$ & $5,1 \pm 4,0$ & 1,5 & 13,3 & $-22,9 \times 10^{-3}$ \\
\hline $\operatorname{NID}(\mu \mathrm{Mol})$ & $19,7 \pm 12,4$ & 6,1 & 42,7 & $-64,0 \times 10^{-3}$ \\
\hline $\mathrm{PO}_{4}^{3-}(\mu \mathrm{Mol})$ & $0,58 \pm 0,30$ & 0,29 & 1,36 & $-5,0 \times 10^{-3}$ \\
\hline Si $(\mu \mathrm{Mol})$ & $33,9 \pm 22,8$ & 9,7 & 69,9 & $-222,8 \times 10^{-3}$ \\
\hline
\end{tabular}

Tabela 2: Sumário dos parâmetros medidos e analisados do estuário do Rio dos Defuntos. V.C.: velocidade de corrente (média de 10 minutos para cada hora cheia); MPS: material particulado em suspensão; O.D.: oxigênio dissolvido; $\mathrm{NH}_{4}{ }^{+}$: amônia; $\mathrm{NO}_{2}{ }^{-}+\mathrm{NO}_{3}$ : nitrato e nitrito; NID: nitrogênio inorgânico dissolvido; $\mathrm{PO}_{4}{ }^{3-*}$ : fosfato; Si: silício; D.P.: desvio padrão; T.R.: transporte residual (negativo significa saída, e positivo entrada, e o mesmo vale para a velocidade).

\begin{tabular}{|c|c|c|c|c|}
\hline Parâmetro & Média e D.P. & Mínimo & Máximo & $\begin{array}{c}\text { T.R. } \\
\left(\mathrm{kg} \cdot \mathrm{m}^{-2} \cdot \text { ciclo }^{-1}\right)\end{array}$ \\
\hline V.C. $\left(m \cdot s^{-1}\right)$ & $-0,04 \pm 0,12$ & $-0,22$ & 0,23 & \\
\hline Salinidade (\%०) & $27,5 \pm 1,8$ & 23,1 & 30,5 & \\
\hline Temperatura $\left({ }^{\circ} \mathrm{C}\right)$ & $19,8 \pm 1,0$ & 17,8 & 21,8 & \\
\hline $\operatorname{MPS}\left(\mathrm{mg} . \mathrm{I}^{-1}\right)$ & $46 \pm 37$ & 8 & 173 & $+5,0$ \\
\hline O.D. (mg. I $^{-1}$ ) & $7,4 \pm 1,9$ & 3,9 & 11,0 & \\
\hline $\mathrm{pH}$ & $7,6 \pm 0,3$ & 7,0 & 8,1 & \\
\hline $\mathrm{NH}_{4}^{+}(\mu \mathrm{Mol})$ & $13,6 \pm 3,9$ & 8,7 & 19,3 & $-9,9 \times 10^{-3}$ \\
\hline $\mathrm{NO}_{2}^{-}+\mathrm{NO}_{3}^{-}(\mu \mathrm{Mol})$ & $5,1 \pm 1,4$ & 3,3 & 7,8 & $-1,0 \times 10^{-3}$ \\
\hline $\operatorname{NID}(\mu \mathrm{Mol})$ & $18,7 \pm 4,8$ & 12,3 & 26,0 & $-10,9 \times 10^{-3}$ \\
\hline $\mathrm{PO}_{4}{ }^{3-}(\mu \mathrm{Mol})$ & $0,67 \pm 0,19$ & 0,52 & 1,03 & $-1,7 \times 10^{-3}$ \\
\hline Si $(\mu \mathrm{Mol})$ & $52,3 \pm 11,8$ & 33,2 & 67,9 & $-94,0 \times 10^{-3}$ \\
\hline
\end{tabular}

\section{Corrente longitudinal}

Considerando os dados reduzidos pelas médias de 10 minutos a cada hora cheia, a velocidade de corrente média foi bastante similar em ambos os estuários, em torno de $-0,03 \mathrm{~m} \cdot \mathrm{s}^{-1}$. Este valor próximo de zero indica que a amostragem foi eficiente em abranger ciclos completos de maré, validando as esti- mativas de transporte. As velocidades máximas, por outro lado, foram bem distintas, sendo os valores observados no ERT 0,15 m.s. superiores aos observados no ERD, tanto para as correntes de enchente quanto de vazante. A magnitude das correntes de enchente e vazante apresentaram-se praticamente iguais em ambos os estuários, a despeito da desigualdade semi-diurna da maré. 


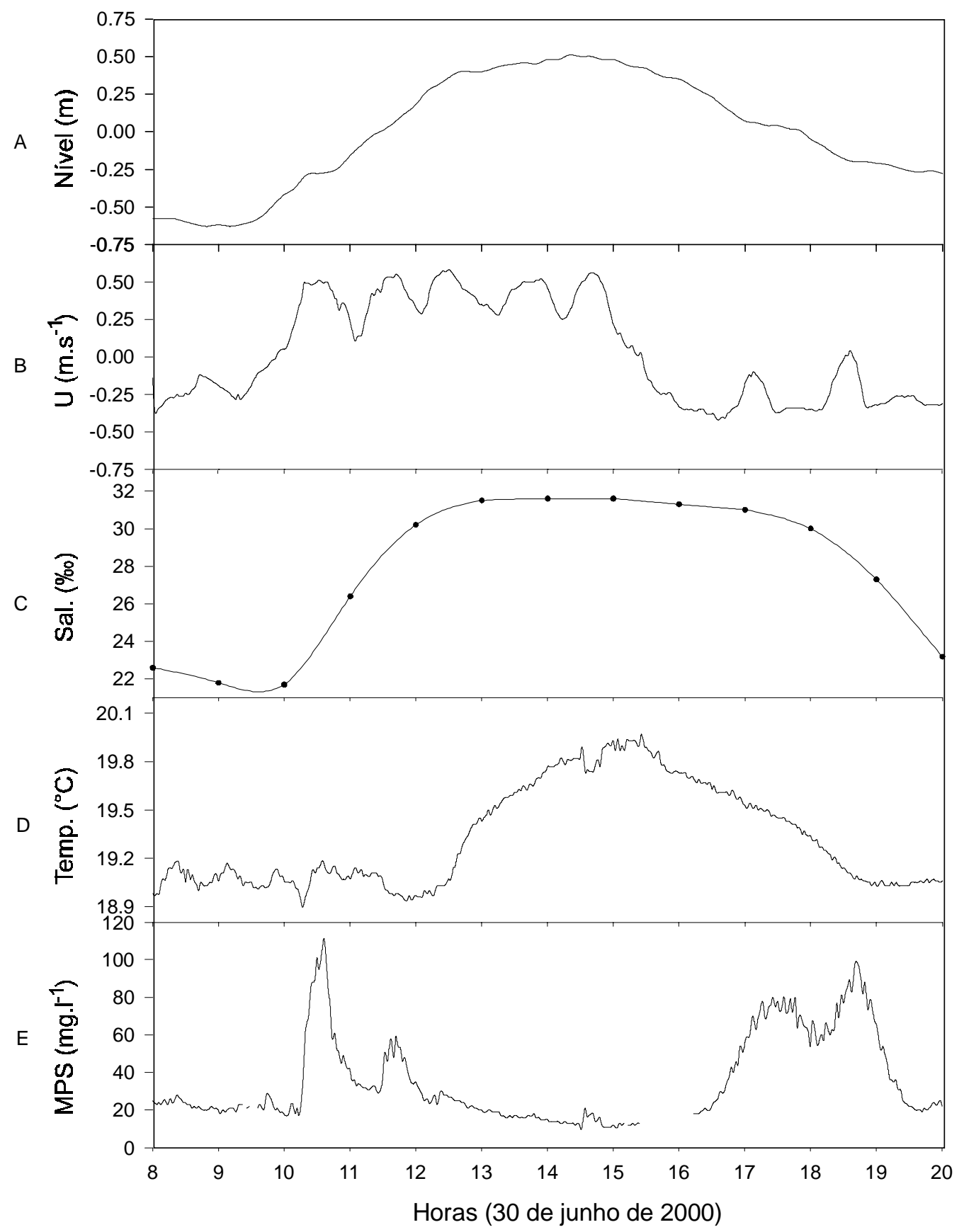

Figura 3: Variação temporal dos parâmetros coletados in situ no estuário do Rio Tavares. A: nível da água, resolução temporal $(\mathrm{rt})=10 \mathrm{~min}$; B: velocidade de corrente, negativa significa escoamento para jusante, $\mathrm{rt}=2 \mathrm{~min}$; $\mathrm{C}$ : salinidade, $\mathrm{rt}=1$ hora; $\mathrm{D}$ : temperatura, $\mathrm{rt}=2 \mathrm{~min}$; e $\mathrm{E}$ : material particulado em suspensão, $\mathrm{rt}=2 \mathrm{~min}$. 


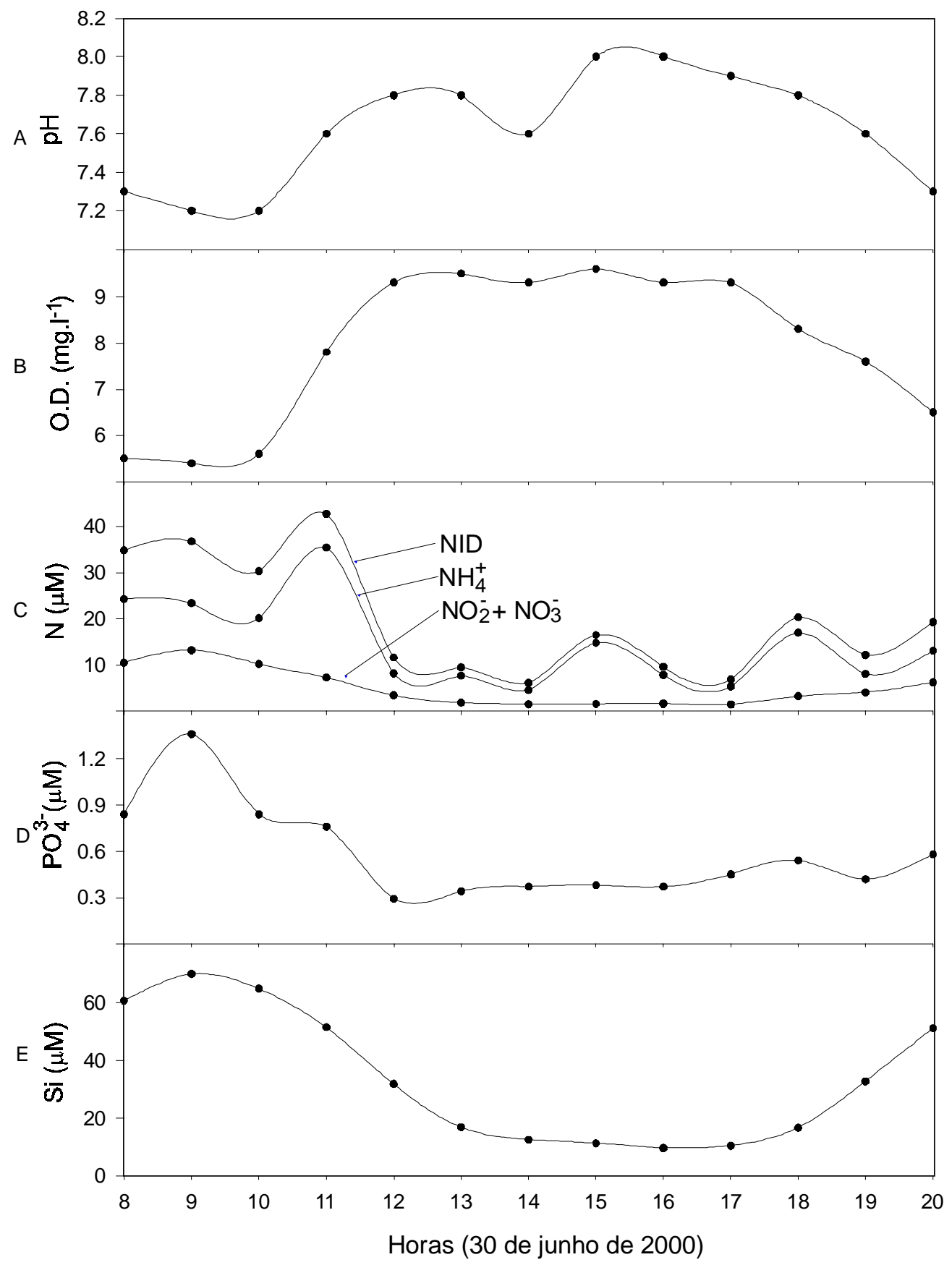

Figura 4: Variação temporal dos parâmetros biogeoquímicos no estuário do Rio Tavares. A: $\mathrm{pH}$; B: oxigênio dissolvido; C: nitrogênio inorgânico dissolvido (NID), amônio $\left(\mathrm{NH}_{4}^{+}\right)$e nitrito + nitrato $\left(\mathrm{NO}_{2}{ }^{-}+\mathrm{NO}_{3}{ }^{-}\right)$; D: fosfato $\left(\mathrm{PO}_{4}{ }^{3}\right)$; e E: silicato (Si). 


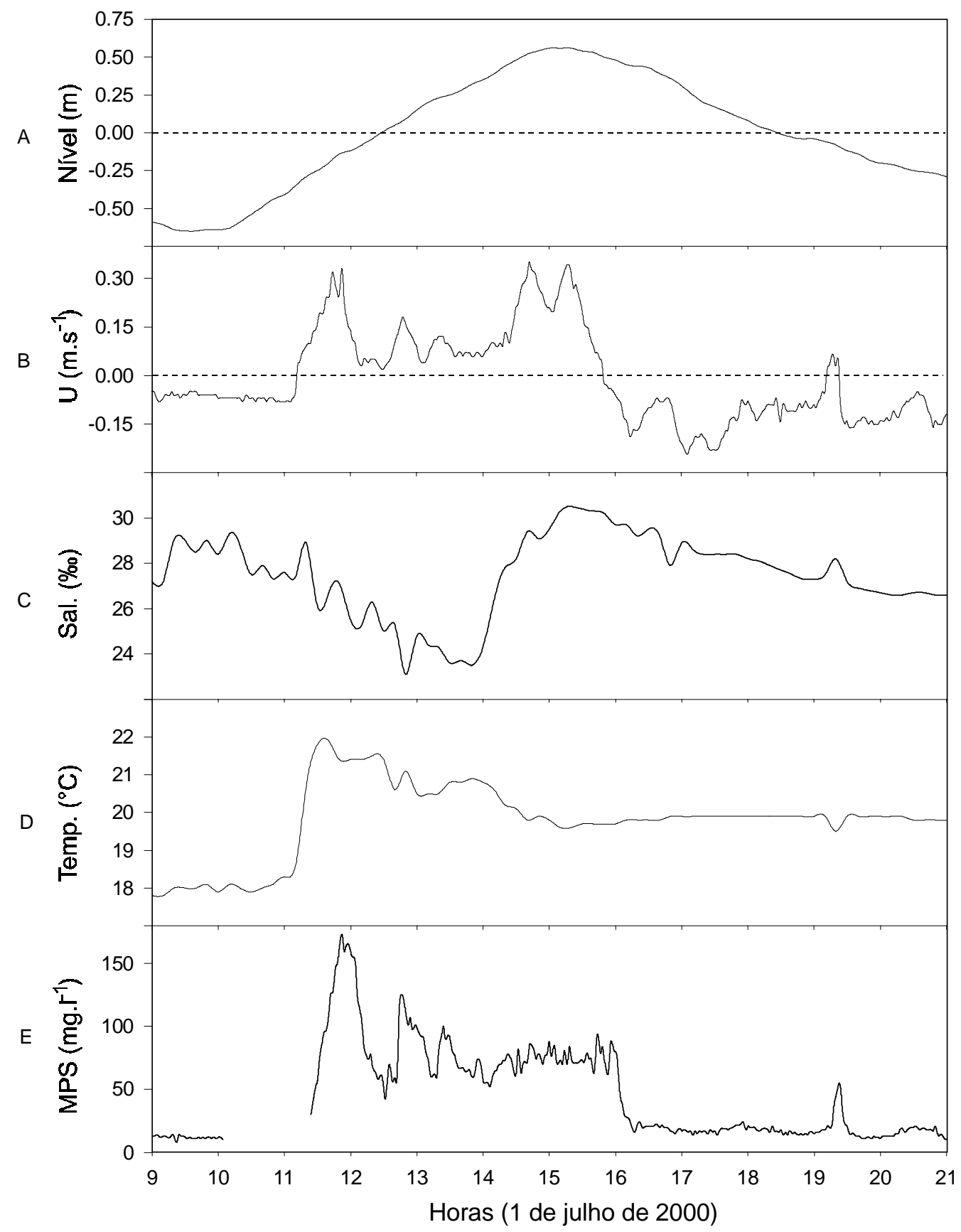

Figura 5: Variação temporal dos parâmetros coletados ín situ no estuário do Rio dos Defuntos. A: nível da água, resolução temporal $(\mathrm{rt})=10 \mathrm{~min}$; $\mathrm{B}$ : velocidade de corrente, negativa significa escoamento para jusante, $\mathrm{rt}=2 \mathrm{~min}$; C: salinidade, $r t=10 \mathrm{~min}$; D: temperatura, $\mathrm{rt}=10 \mathrm{~min}$; e E: material particulado em suspensão, $\mathrm{rt}=2 \mathrm{~min}$. 


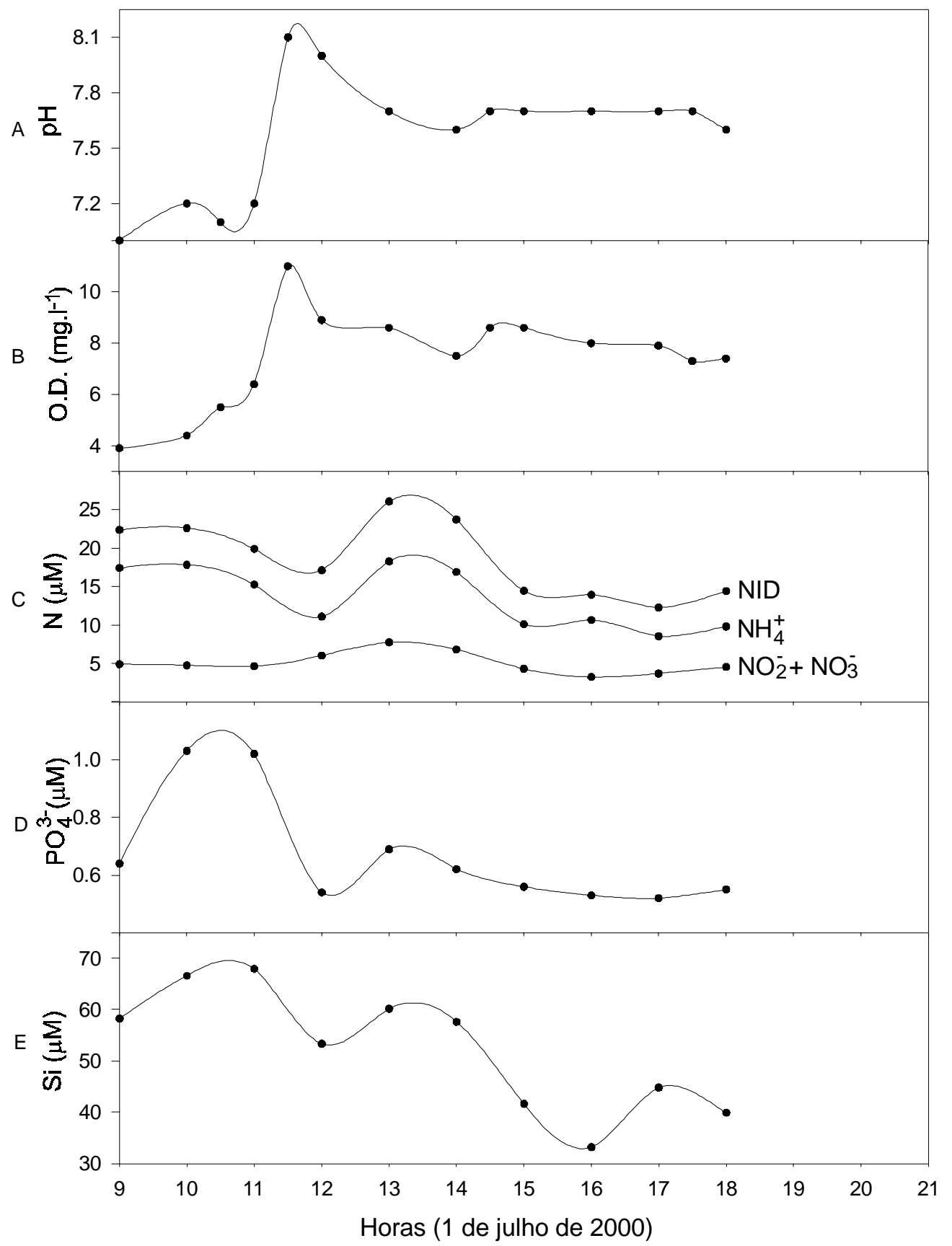

Figura 6: Variação temporal dos parâmetros biogeoquímicos no estuário do Rio dos Defuntos. $\mathrm{A}$ : $\mathrm{pH}$; B: oxigênio dissolvido; C: nitrogênio inorgânico dissolvido (NID), amônio $\left(\mathrm{NH}_{4}^{+}\right)$e nitrito + nitrato $\left(\mathrm{NO}_{2}{ }^{-}+\mathrm{NO}_{3}{ }^{-}\right)$; D: fosfato $\left(\mathrm{PO}_{4}{ }^{3-}\right)$; e E: silicato (Si). 
A variação da velocidade de corrente no ERT acompanhou de maneira coerente a variação do nível da água, contudo apresentando uma notável oscilação em torno de $0,20 \mathrm{~m} \cdot \mathrm{s}^{-1}$, com período aproximado de 1 hora, tanto no período de enchente quanto que no de vazante. Uma outra feição observada foi a aparente estabilização das velocidades máximas de enchente e vazante, invertendo-se em função da maré, em torno de $+0,50 \mathrm{~m} . \mathrm{s}^{-1} \mathrm{e}-0,40$ $\mathrm{m} . \mathrm{s}^{-1}$, respectivamente (Figura $3 \mathrm{~B}$ ).

$A$ variação temporal da velocidade de corrente no ERD foi ainda mais peculiar do que a observada no ERD. Até aproximadamente às 11:00, a velocidade apresentou-se estável em - 0,08 m.s ${ }^{-1}$, virando e subindo até + 0,25 m.s ${ }^{1}$ até às 11:30, e oscilando a partir de então de maneira similar ao observado no ERT. Contudo, os picos de oscilação variaram bastante, chegando ao máximo de $+0,35 \mathrm{~m} \cdot \mathrm{s}^{-1}$ às 15:20, próximo da preamar. Após a virada da maré a corrente inverteu para vazante, oscilando com menor amplitude em torno de $-0,15 \mathrm{~m} . \mathrm{s}^{-1}$ (Figura 5B). Pouco após às 19:00 ocorreu um período de enchente de 10 minutos, com reflexo também na salinidade, temperatura e MPS.

\section{Salinidade e temperatura}

A salinidade média no ERT foi $30,1 \pm$ $4,6 \%$, tendo uma variação máxima de $15 \%$, e no ERD a salinidade média foi $27,5 \pm 1,8 \%$, com variação menor de $7 \%$. Ambos os estuários apresentaram distribuição vertical homogênea. A salinidade apresentou resposta coerente com a maré no ERT, com valores mínimos de $22 \%$ na baixamar, às 9:00 e 10:00, subindo com a elevação da maré até $32 \%$, às 11:00, permanecendo estável até às 18:00 quando começou a diminuir (Figura 3C). No $E R D$, em função de que o CTD coletou informações à cada 10 minutos, foi possível verificar a variação da salinidade com melhor resolução temporal. Durante a baixamar, a salinidade era de $29 \%$, e ao contrário do observado no ERT, ela diminui com a subida da maré até às $14: 00$, atingindo $23 \%$. A partir deste ponto observou-se uma rápida elevação até $31 \%$ às 15:30, e uma nova diminuição, menos intensa do que a observada anteriormente, até o fim da campanha (Figura 5C).

A temperatura apresentou valor médio em torno de $19,5^{\circ} \mathrm{C}$ em ambos os estuários, com maior amplitude de variação para o ERD, $4^{\circ} \mathrm{C}$, enquanto que a variação no ERT foi de 1 ${ }^{\circ} \mathrm{C}$. A temperatura no ERT seguiu o padrão da salinidade, porém elevando depois e diminuindo antes que esta. A temperatura permaneceu estável em torno $19^{\circ} \mathrm{C}$ do início da campanha até às 12:00, subindo a partir de então até às $15: 00$, atingindo o máximo de $19,9^{\circ} \mathrm{C}$, e voltando a diminuir até às 19:00, e aparentemente estabilizando-se novamente em torno de 19,0 ${ }^{\circ} \mathrm{C}$ (Figura 3D). No ERD, a temperatura permaneceu estável até às 11 , em torno de $18^{\circ} \mathrm{C}$, apresentando uma repentina elevação até quase $22,0^{\circ} \mathrm{C}$ às $11: 30$, diminuindo a partir de então até às 15:00 e estabilizando até o final da campanha em torno de $19,8^{\circ} \mathrm{C}$ (Figura 5D).

\section{Material particulado em suspensão - MPS}

A concentração média de MPS no ERT foi $36 \pm 24 \mathrm{mg} . \mathrm{l}^{-1}$, um pouco menor ao encontrado no ERD, $46 \pm 37 \mathrm{mg} . \mathrm{I}^{-1}$. Os valores mínimos foram 11 e 8 mg..$^{-1}$ e máximos foram 111 e $177 \mathrm{mg} . \mathrm{I}^{-1}$, para ERT e ERD, respectivamente. No ERT o MPS permaneceu estabilizado em torno de $20 \mathrm{mg}^{-1} \mathrm{I}^{-1}$ durante a baixamar, subindo repentinamente até mais de $100 \mathrm{mg} . \mathrm{I}^{-1}$ no início da enchente, às 10:30, porém voltando a diminuir rapidamente pouco tempo após para $40 \mathrm{mg.l}^{-1}$. Próximo às 11:30 houve um novo pico no MPS, porém atingindo $60 \mathrm{mg} . \mathrm{l}^{-1}$, e retornando a descer. Das 12:00 até às 16:30 o MPS permaneceu baixo, $20 \mathrm{mg} . \mathrm{l}^{-1}$, subindo até 80 mg..$^{-1}$ no fim da vazante após às 17:00, permanecendo elevado e com a ocorrência de um pico máximo, pouco antes das 19:00, a partir

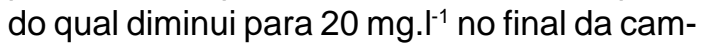
panha (Figura 3E).

No ERD o MPS também permaneceu estável em torno de $15 \mathrm{mg} . \mathrm{I}^{-1}$ até o início da enchente, onde elevou-se até mais de 150 
mg..$^{-1}$ às 12:00. Durante o período de enchente o MPS apresentou vários picos de intensidade decrescente até às 14:00, apresentando a partir de então oscilações menores em torno de $75 \mathrm{mg} . \mathrm{l}^{-1}$. Pouco a pós o início da vazante, às 16:00, o MPS diminuiu rapidamente para 15 mg..$^{-1}$, permanecendo assim até o final da campanha, com exceção de um curto pico às 19:30 (Figura 5E).

\section{pHe oxigênio dissolvido-OD}

$\mathrm{O} \mathrm{pH}$ apresentou valores médios praticamente iguais em ambos os estuários, 7,6 \pm 0,3 , com uma variação um pouco maior no ERD, onde variou de 7,0 até 8,1 . Em ambos estuários o $\mathrm{pH}$ respondeu diretamente à variação de maré, com valores menores na baixamar, aumentando na preamar. No ERT a variação do $\mathrm{pH}$ foi bem similar à da salinidade (Figura 4A). No ERD observou-se um pico imediatamente após o início da subida da maré, acima de 8, decaindo após e estabilizando em torno de 7,7 (Figura 6A).

O comportamento do O.D. foi bastante similar ao observado para o $\mathrm{pH}$. A concentração média de oxigênio dissolvido foi similar em ambos os estuários, 7,9 \$1,6 e 7,4 \$1,9 para ERT e ERD, respectivamente, com variação mais expressiva para o último, de 3,9 até 11,0 mg. ${ }^{1-1}$, enquanto que no ERT variou de 5,4 até 9,6 mg. l $^{-1}$. No ERT o O.D. variou sem mudanças bruscas, acompanhando as fases da maré (Figura 4B); no ERD houve também um pico máximo logo no início da subida da maré, alcançando $11 \mathrm{mg}^{-1} \mathrm{I}^{-1}$, diminuindo e estabilizando em torno de $8 \mathrm{mg}^{\mathrm{I}^{-1}}$ depois (Figura $6 \mathrm{~B}$ ).

\section{Nutrientes inorgânicos dissolvidos}

Embora os nutrientes inorgânicos dissolvidos tenham apresentados valores médios dentro de uma mesma ordem de grandeza em ambos os estuários, as variações máximas de todos foram maiores no ERT. A concentração média de amônio $\left(\mathrm{NH}_{4}^{+}\right)$foi $14,6 \pm 9,2 \mu \mathrm{M}$, variando de 4,6 até 35,5 $\mu \mathrm{M}$ no ERT, e 13,6 \pm 3,9 $\mu \mathrm{M}$, variando de 8,7 até $19,3 \mu \mathrm{M}$ no ERD. A concentração média da soma do nitrito e nitrato $\left(\mathrm{NO}_{2}^{-}+\mathrm{NO}_{3}{ }^{-}\right)$foi $5,1 \pm 4,0 \mu \mathrm{M}$, variando de 1,5 até $13,3 \mu \mathrm{M}$ no ERT, e 5,1 $\pm 1,4 \mu \mathrm{M}$, variando de 3,3 até 7,8 $\mu \mathrm{M}$ no ERD. A concentração média de fosfato $\left(\mathrm{PO}_{4}{ }^{3-}\right)$ foi $0,58 \pm 0,30 \mu \mathrm{M}$, variando de 0,29 até $1,36 \mu \mathrm{M}$ no ERT, e 0,67 \pm $0,19 \mu \mathrm{M}$, variando de 0,52 até $1,03 \mu \mathrm{M}$ no ERD.

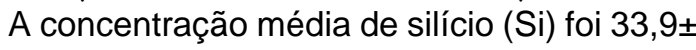
$22,8 \mu \mathrm{M}$, variando de 9,7 até $69,9 \mu \mathrm{M}$ no ERT, e $52,3 \pm 11,8 \mu \mathrm{M}$, variando de 33,2 até $67,9 \mu \mathrm{M}$ no ERD.

O NID no ERT apresentou valores em torno de $35 \mu \mathrm{M}$ durante a baixamar, com um pico de máxima às 11:00, alcançando quase $43 \mu \mathrm{M}$, e depois decaindo para valores em torno de $10 \mu \mathrm{M}$, e apresentando picos menores às 15:00 e às 18:00 de $20 \mu \mathrm{M}$. A variação do NID foi determinada diretamente pela concentração de $\mathrm{NH}_{4}{ }^{+}$. O NO${ }_{2}^{-}+\mathrm{NO}_{3}^{-}$apresentaram o maior valor às 9:00, 13 $\mu \mathrm{M}$, e depois decaindo e permanecendo em torno de 1,5 $\mu \mathrm{M}$ até às 17:00, e voltando a subir com a descida da maré (Figura 4C). No ERD a variação do NID e do $\mathrm{NH}_{4}{ }^{+}$foi mais ou menos similar, porém com o pico de máxima ocorrendo com uma hora de atraso de fase em relação ao observado no ERT, às 13:00. $\mathrm{O} \mathrm{NO}_{2}^{-}+\mathrm{NO}_{3}^{-}$apresentou valores baixo na baixamar, e subindo até seu valor máximo durante o pico de $\mathrm{NH}_{4}^{+}$, e depois retornando a cair para os níveis encontrados na baixamar (Figura 6C).

$\mathrm{O} \mathrm{PO}_{4}^{3-}$ em ambos os estuários apresentou os valores máximos na baixamar e no início da enchente, às 9:00 no ERT, e às 10:00 e 11:00 no ERD, e depois decaindo e permanecendo em um patamar de 0,4 $\mu \mathrm{M}$ até o fim das campanhas (Figuras 3D e 5D). O Si no ERT apresentou um comportamento diretamente inverso ao da salinidade, com pico máximo observado às 9:00 na baixamar, e mínimo durante o final da enchente até o fim da vazante (Figura 3E). No ERD o comportamento do Si foi bem mais complexo, sendo que o máximo também foi observado durante a baixamar, contudo não decaindo da mesma maneira como 
observado no ERT, e apresentando-se bastante irregular durante todo o período (Figura 5E).

\section{DISCUSSÃO}

Os dois estuários estudados neste trabalho, apesar de estarem distantes menos de $1 \mathrm{~km}$ um do outro, apresentaram diferenças significativas na maior parte dos parâmetros monitorados. O comportamento diferenciado entre eles está relacionado com as características fisiográficas e hidrológicas de cada sistema. O bacia hidrográfica do Rio Tavares apresenta $27,5 \mathrm{~km}^{2}$, enquanto que a do Rio dos Defuntos apresenta apenas $3,5 \mathrm{~km}^{2}$. Além das diferenças de dimensões de suas respectivas bacias, a maior parte da bacia do Rio dos Defuntos está situada em uma região de manguezal, com pouca utilização urbana. Por outro lado, grande parte da bacia do Rio Tavares apresenta-se ocupada por aglomerados urbanos da cidade de Florianópolis e zonas agropecuárias, o que certamente acarreta uma maior carga de efluentes.

O ERT deságua no Saco dos Limões no seu extremo sul, no limite do aterro hidráulico. Ali ainda encontram-se diversos pescadores e há um canal dragado conectando esta região com as partes mais profundas do saco para permitir a navegação mesmo durante a maré baixa. Esta conexão faz com que as águas do ERT sejam mais efetivamente trocadas a cada ciclo de maré com o saco. No ERD, por outro lado, a circulação durante a baixamar de sizígia fica totalmente restrita pela planície de maré que se prolonga centenas de metros para o interior do saco. Isto faz com que as trocas de águas sejam efetivas somente acima de um determinado nível.

Um outro aspecto a ser considerado como determinante das variações intra-mareais observadas em ambos estuários é o fato de desaguarem em um corpo estuarino maior, no caso, a Baía Sul. O complexo estuarino das Baías Norte e Sul recebe o aporte de inúmeros pequenos estuários, sendo o maior destes o do Rio Cubatão, na margem continental da Baia
Sul. A hidrodinâmica destes estuários internos, similar ao que ocorreria em estuários desaguando diretamente no oceano, é controlada principalmente pela descarga fluvial e oscilações de maré. Contudo, um outro aspecto que se torna relevante nestes ambientes é a oscilação natural do corpo receptor. A oscilação natural do sistema, ou seiche, é função da sua extensão horizontal e profundidade, e ocorre em qualquer corpo de água restrito. Em função da complexidade da gemorfologia da bacia, muitos modos de oscilação podem estar presentes, e.g., longitudinais e transversais (Pugh, 1987). No registro de nível de água (Figura 2) a oscilação mais notável está claramente relacionada com o sinal semi-diurno, de aproximadamente 12 horas, sendo as demais oscilações praticamente imperceptíveis. Porém, o espectro de potência do sinal (Figura 7), indica a presença de oscilações de períodos menores também associadas à oscilações de maré astronômicas, de 6 e 4 horas de período, bem como oscilações de períodos menores ainda com picos em 1,92, 1,48, 1,14 e 0,98 horas. Estas últimas possívelmente são seiches gerados a partir de diversos modos de oscilações naturais do complexo de baías.

Embora os seiches sejam pouco notáveis no sinal de nível de água, o sinal de correntes longitudinais no ERT apresentou uma destacada variação de intensidade com período aproximado de 1 hora (Figura 3B). Esta variação de intensidade coincide em período com os picos no espectro de potência (Figura 7), para a região de 1 até 1,5 horas. Porém, a maior densidade espectral do nível de água está associada à um período de 2 horas. Esta diferença pode ser interpretada pela posição do estuário no limite leste da baía, estando assim mais sujeito à oscilações laterais, estimadas em torno de 1 hora a partir dos registros de correntes. As oscilações de 2 horas de período talvez estejam relacionadas mais diretamente ao eixo longitudinal do complexo de baías, onde induziriam maiores amplitudes no estreito ou nas barras. Também foram observadas oscilações no sinal de velocidade longitudinal no ERD, 
principalmente durante o período de enchente, porém não tão regulares quanto às observadas no ERT (Figura 5B). Este comportamento possivelmente é resultado da complexidade da circulação sobre o plano de maré e no interior do manguezal, onde a pouca profundidade induz à um maior efeito friccional do fundo sobre o escoamento.

A despeito da complexidade do sinal de correntes no ERT, a salinidade apresentou boa coerência com a variação da maré (Figura $3 C$ ). $\mathrm{O}$ fato de ocorrer a estabilização do sinal em torno de $32 \%$ o com a enchente possivelmente está relacionado com a salinidade média presente no complexo de baías, e a menor salinidade observada durante os períodos de baixamar associada com efeitos locais próximos da margem do Saco dos Limões e pela diluição causada pelo aporte fluival da bacia do Rio Tavares. No ERD a variação da salinidade não seguiu o mesmo comportamento, onde foi observado que a salinidade diminuiu com a subida da maré, aumentando somente próxi- mo da preamar, a partir de então baixando com o descida da maré (Figura 5C). Isto pode ser interpretado pela pequena bacia de drenagem que este estuário apresenta, sendo então que as variações da salinidade são mais diretamente influenciadas por variações que ocorrem no Saco dos Limões. Considerando a menor amplitude de variação da salinidade no ERT, e que a menor salinidade observada foi um pouco superior à mínima observada no ERD, é possível explicar a diminuição desta com a subida da maré considerando que a água que entrou durante a maior parte da fase de enchente como sendo da pluma estuarina do ERD dispersada para oeste durante a baixamar. Este padrão sugere que durante a condição amostrada, houve uma circulação residual com sentido horário no interior do Saco dos Limões, com deslocamento de leste para oeste na região do plano intermareal defronte aos estuários.

A variação da temperatura no ERT foi relativamente discreta ao longo do período ob-

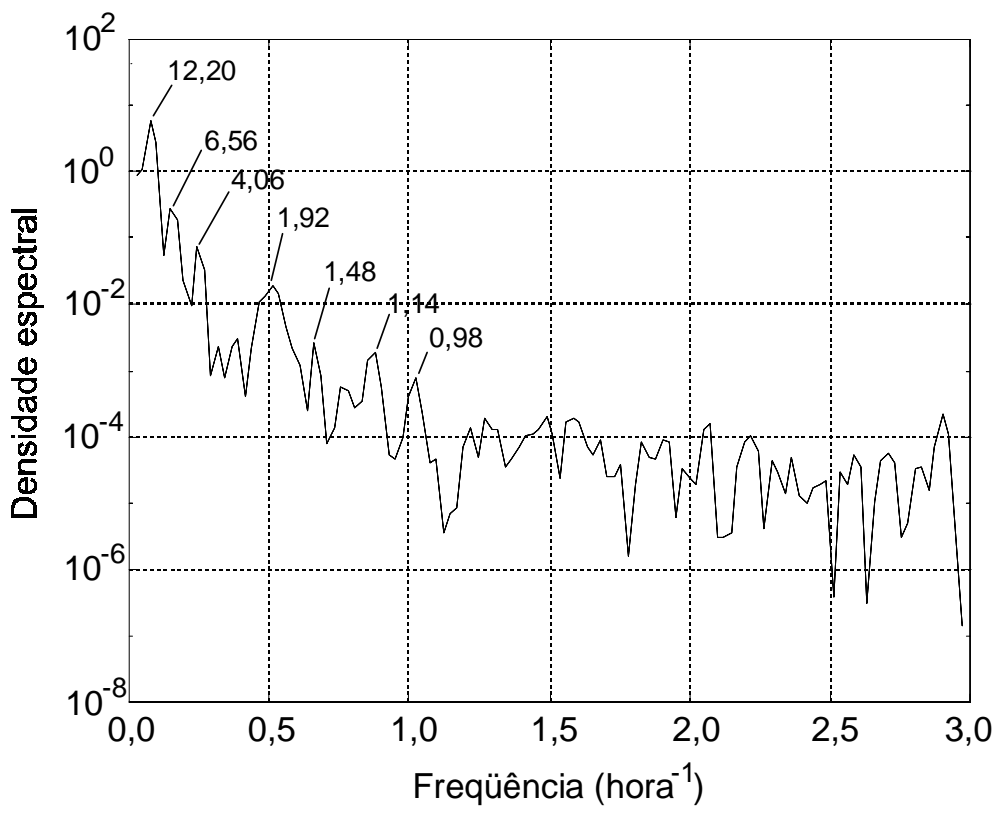

Figura 7: Distribuição de densidade espectral dos dados de nível de água próximo ao estreito de Florianópolis. Os números indicadores dentro do gráfico estão em horas. 
servado, sendo provavelmente causada pela oscilação térmica diurna, por troca direta com a atmosfera. Por outro lado, o mesmo não foi observado no ERD. Das 9 até às 11 horas a temperatura permaneceu estável, em torno de $18^{\circ} \mathrm{C}$, subindo rapidamente e atingindo seu pico máximo de $22^{\circ} \mathrm{C}$ logo no início da enchente, e passando a diminuir e estabilizando (Figura 5D). Durante a baixamar toda o plano de maré estava exposto diretamente à radiação solar. Durante o período de coleta praticamente não havia cobertura de núvens, o que causou a absorção de enegia pelo sedimento. A medida que a maré subiu, calor foi transferido para a água de contato de enchente, e quando esta passou através da seção de amostragem refletiu no pico de máxima temperatura. Com a subida da maré e consequentemente um maior volume de água sobre o plano, este processo deixou de ser importante e provavelmente durante o resto do período a temperatura variou em função de trocas diretas com a atmosfera similar ao observado no ERT.

A concentração de MPS no ERT apresentou dois picos distintos durante a enchente, e outros dois durante a vazante. Em ambos os casos a diferença entre picos foi aproximadamente 1 hora (Figura 3E). Comparativamente, na enchente o primeiro pico foi superior ao segundo, e o contrário foi observado para os picos de vazante; também, os picos de enchente apresentam também menor espraiamento temporal do que os picos observados de vazante. Este padrão sugere a existência de duas zonas de maior turbidez associadas com a entrada e saída de água do ERT. Considerando a diferença no espraiamento temporal dos picos de enchente e vazante, supõe-se que a origem do MPS está no interior do estuário. Durante a vazante estas massas de água com maior concentração de MPS são espraiadas na região vizinha à desembocadura formando a pluma fluvial do ERT, com retorno parcial deste material durante a enchente. O processo de retorno parcial de massas de água corrobora às observações de salinidade do ERD, onde a diminuição da salinidade com a subida da maré seria causada pela pluma estuarina do ERT que não retornou para este. No ERD, a máxima concentração de MPS observada logo no início da enchente após um período inicial de baixa concentração nas primeiras horas (Figura 5E), é interpretado como efeitos da ação da resuspensão de sedimentos do plano intemareal por ondas de vento. A medida que 0 nível de água sobe, o plano de maré é gradualmente submerso, formando uma zona de máxima turbidez associada com a água de contato de enchente. As variações posteriores podem ter sido causadas também por variações do regime hidrodinâmico do saco. A abrupta diminuição logo no início da vazante, quando a

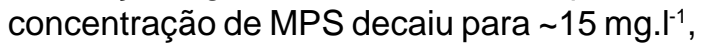
reflete o comportamento do manguezal como bacia de sedimentação. Durante as últimas horas de enchente e início da vazante o manguezal foi alagado. Devido à densa vegetação a superfície da água nesta região praticamente não sofre influência direta do vento, e a presença de caules e raízes aéreas aumenta a fricção do escoamento resultando em velocidades de corrente bastante baixas, acarretando a sedimentação do MPS. Com a vazante, o canal do ERD atua como dreno da água que se encontrava no maguezal com baixa concentração de MPS, uma vez que uma parte significativa deste sedimentou. $O$ transporte residual de MPS reflete estes padrões, onde o ERT atua com exportador de MPS, enquanto que 0 ERD atua como importador.

As variações temporais do OD e pH foram similares em cada estuário, porém distintas entre eles. No ERT a variação destes dois parâmetros seguiu coerentemente a variação da maré, tal qual foi observado para a salinidade. No ERD, a variação destes parâmetros foi mais similar ao comportamento do MPS, onde se observou um pico máximo no início da enchente, após um período de valores constantes durante a baixamar. Este comportamento está relacionado à hidrodinâmica local associada aos processos biogeoquímicos de produção e decomposição da matéria orgânica nos estuários e no plano intermareal situ- 
ado defronte à eles. No ERT, os menores valores de $\mathrm{pH}$ e OD ocorreram no início da manhã durante a maré baixa, entre 08 e 10 horas (Figura 4). Estes baixos valores podem ser explicados em função da presença de uma água com maior influência fluvial e em função deles representarem o balanço dos processos de produção e mineralização da matéria orgânica ocorridos durante a noite. Durante o período noturno ocorre predominância dos processos de mineralização, os quais resultam no consumo de $\mathrm{OD}$ e na produção de $\mathrm{CO}_{2}$. Assim, durante o ciclo diário é esperado encontrar os menores valores de OD e pH no início da manhã. Além disso, entradas de esgotos no estuário aumentam a carga orgânica, resultando na intensificação dos processos de mineralização. A partir das 10 horas ocorreu o aumento tanto do OD como do $\mathrm{pH}$ paralelamente ao aumento da salinidade com a entrada de água da baía. Este aumento pode ser explicado pela predominância dos processos de produção de matéria orgânica por organismos autotróficos sobre a mineralização. Com a disponibilidade de luz os processos de produção primária tornamse pronunciados, principalmente no plano intermareal situado em frente ao estuário, uma vez que recebe o aporte de nutrientes do estuário. O mesmo mecanismo explica as variações do $\mathrm{pH}$ e OD no ERD. Entretanto, durante os momentos de maré baixa este estuário fica isolado da baía, de modo que os processos biogeoquímicos associados ao mangue predominam. Neste estudo foram obsrvados valores baixos de $\mathrm{pH}$ e OD até as 11:00 horas (Figuras $6 \mathrm{~A}$ e $\mathrm{B}$ ), em um período de maré baixa. Com a elevação da maré, verificou-se o aumento destes parâmetros, o que pode ser explicado pela entrada da água do plano intermareal, o qual apresenta características ideais para os produtores primários, conforme descrito acima.

Em ambos estuários o $\mathrm{NH}_{4}{ }^{+}$foi a principal forma de NID durante toda a campanha, correspondendo em média a $75 \%$ do NID no ERT e 79\% no ERD. Apesar das médias semelhantes, os maiores valores absolutos foram obtidos no ERT. As concentrações de $\mathrm{NH}_{4}{ }^{+}$re- presentam o reflexo das entradas de efluentes e esgotos, e dos processos de reciclagem em ambientes costeiros (Braga et al, 2000). As concentrações elevadas observadas durante a maré baixa refletem o maior grau de influência antropogênica no ERT. Este estuário recebe o esgoto doméstico de várias residências em sua bacia de drenagem e os maiores valores observados são próximos aos encontrados em outros ambientes impactados, como é o caso do estuário do Rio Camboriú (Pereira Filho et al, 2001), situado cerca de $80 \mathrm{~km}$ ao norte. Este estuário recebe uma grande carga de esgotos clandestinos, além do efluente da estação de tratamento de esgoto do município de Balneário Camboriú. Para termos comparativos, Braga et al (2000), encontraram valores de $\mathrm{NH}_{4}^{+}$próximos a $40 \mu \mathrm{M}$ na região interna do sistema estuarino de Santos e São Vicente, no litoral sul de São Paulo, sendo esta uma região altamente impactada. A dominância de $\mathrm{NH}_{4}^{+}$é indicativo de grande carga orgânica presente, já que esta é a forma de nitrogênio diretamente relacionada à decomposição de matéria orgânica.

No ERD, a predominância de $\mathrm{NH}_{4}^{+}$sobre no NID representa a influência dos processos biogeoquímicos de degradação da matéria orgânica que ocorrem no mangue e na região adjacente sobre a composição da água estuarina. O ERD, consistindo basicamente de um pequeno canal de maré, sofre influência mais direta do mangue, o qual é um ambiente de acúmulo de matéria orgânica. A matéria orgânica acumulada no sedimento, ao ser decomposta, pode levar a diminuição substancial do OD, principalmente quando o canal fica isolado da baía durante a maré baixa. Particularmente nos períodos do início da manhã, se a maré estiver baixa, $O$ OD pode cair a tal ponto na coluna d'água que o ambiente pode se tornar redutor, o que explicaria a predominância do $\mathrm{NH}_{4}{ }^{+}$. Os maiores valores de $\mathrm{NH}_{4}{ }^{+}$foram registrados às 13:00 e 14:00 horas, quando também foi o período de menor salinidade neste estuário. Entretanto, a diminuição de salinidade ocorreu durante a enchente, ao con- 
trário do que seria esperado, porém explicado pelo padrão de circulação do Saco dos Limões explicado acima. Parte do $\mathrm{NH}_{4}^{+}$observado no ERD pode ter sido originado no ERT.

Além do $\mathrm{NH}_{4}^{+}$, o NID é composto pelo $\mathrm{NO}_{3}^{-}$e pelo $\mathrm{NO}_{2} \cdot \mathrm{O} \mathrm{NO}_{3}^{-}$normalmente é a forma predominante de NID em águas bem oxigenadas com baixa atividade biológica, pois é a forma mais oxidada dos nutrientes nitrogenados (Spencer, 1975; Chester, 1990). $\mathrm{ONO}_{2}$-representa o estado intermediário entre

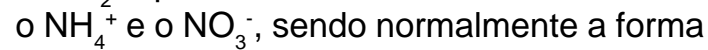
menos abundante em ambientes aquáticos. Ele pode ser formado tanto pela oxidação do $\mathrm{NH}_{4}{ }^{+}$, em condições óxicas, como pela redução do $\mathrm{NO}_{3}$, em condições anóxicas. Neste estudo as duas formas não foram separadas, sendo consideradas em conjunto. Em ambientes oxigenados com baixa atividade biológica e onde os processos de decomposição de matéria orgânica não são pronunciados, o NID está presente principalmente na forma de $\mathrm{NO}_{3}$. Isto ocorre em função da oxidação bacteriana do $\mathrm{NH}_{4}{ }^{+} \mathrm{em} \mathrm{NO}_{2}{ }^{-}$e deste em $\mathrm{NO}_{3}{ }^{-}$, num processo denominado de nitrificação, e o $\mathrm{NO}_{3}{ }^{-}$é a forma mais estável sob estas circunstâncias. No caso de ambos os estuários, a pequena proporção do $\mathrm{NO}_{2}{ }^{-}+\mathrm{NO}_{3}{ }^{-}$sobre o NID é um indicativo da presença de grandes quantidades de matéria orgânica e dos processos associados à sua degradação, os quais resultam em $\mathrm{NH}_{4}^{+}$. Tanto para o ERT como para o ERD, o comportamento do $\mathrm{NO}_{3}{ }^{-}$foi similar, sendo que os valores obtidos em ambos ficaram muito próximos. Sendo ambientes oxigenados e com grande disponibilidade de $\mathrm{NH}_{4}^{+}$, o $\mathrm{NO}_{2}^{-}$e o $\mathrm{NO}_{3}^{-}$são constantemente formados pela nitrificação. A intensidade deste processo aumenta com a disponibilidade de $\mathrm{NH}_{4}{ }^{+}$, originado da decomposição orgânica, estimulando o desenvolvimento da flora bacteriana nitrificante. Assim, os maiores valores de $\mathrm{NO}_{2}{ }^{-}+\mathrm{NO}_{3}{ }^{-}$coincidiram com os períodos de maior concentração de $\mathrm{NH}_{4}{ }^{+}$, registrados nos períodos de menor salinidade.

O comportamento do $\mathrm{PO}_{4}{ }^{3-}$ seguiu a mesma tendência dos demais nutrientes no
ERT, com os maiores valores sendo registrados nos períodos de maior influência de água fluvial. As menores concentrações registradas nos períodos de maré alta resultam da diluição das águas fluviais, ricas em $\mathrm{PO}_{4}{ }^{3-}$, pelas águas da baía com menores quantidades deste nutriente. No ERD esta tendência não fica tão clara, já que as trocas com a baía não são tão efetivas. Neste estuário os processos biogeoquímicos relacionados à decomposição da matéria orgânica assumem uma maior importância do que a simples diluição das águas fluviais pela entrada da água salgada. Os maiores valores de $\mathrm{PO}_{4}^{3-}$ no ERD foram registrados no período da manhã, durante a maré baixa. Nesta condição o estuário fica isolado da baía, de modo que os processos de reciclagem da matéria orgânica estuarina exercem grande influência sobre a composição química da água. Estes processos resultam no aumento das concentrações de $\mathrm{PO}_{4}{ }^{3-}$, mesmo sem que ocorra predominância de água fluvial (Figura 6D). Além disso, como neste caso a maré baixa ocorreu pela manhã, após um período sem luz, as variáveis da coluna de água representam o resultado dos processos de mineralização ocorridos durante a noite, conforme mencionado anteriormente, resultando também em baixas concentrações de oxigênio e baixos valores de $\mathrm{pH}$ registrados neste momento. A predominância de $\mathrm{NH}_{4}{ }^{+}$sobre os nutrientes nitrogenados observada neste período é outra evidência deste comportamento.

O comportamento do Si inorgânico dissolvido evidenciou claramente a influência fluvial sobre a distribuição de nutrientes no ERT. As maiores concentrações foram observadas nos momentos de baixa salinidade, aumentando progressivamente com a diminuição da salinidade, evidenciando sua origem às águas fluviais. O Si é originado pelo intemperismo das rochas e não participa diretamente no ciclo da matéria orgânica, a não ser quando ocorre o desenvolvimento de organismos que utilizam este elemento em suas carapaças, tais como as diatomáceas. Dentre os nutrientes, o Si foi o que apresentou o comportamento mais 
conservativo no ERT, mostrando participação discreta nos processos biogeoquímicos deste estuário. Tal qual observado no ERT, os maiores valores de Si no ERD foram registrados nos períodos de menor salinidade. Entretanto, apesar de sofrer menor influência direta da água doce, o ERD apresentou concentrações elevadas de Si quando comparadas às observadas no ERT. Isto pode estar relacionado com a influência dos processos biogeoquímicos que ocorrem no plano intermareal e da pluma estuarina do ERT. Desta forma, o Si inorgânico dissolvido chega à enseada a partir do ERT, na maré baixa. No plano intermareal, um ambiente já com grande influência de água salgada e com baixa turbidez, ocorre o consumo deste Si por organismos silicosos. Este consumo resulta em conversão do Si dissolvido em $\mathrm{Si}$ particulado na forma de estruturas de organismos. O Si particulado como parte do MPS é resuspendido e/ou carreado para o ERD, resultando no pico de turbidez observado no início do período de enchente. No fim do período de enchente e início da vazante, com o manguezal alagado, verifica-se diminuição da dinâmica, propiciando a sedimentação do material particulado como já discorrido acima. Este ambiente propicia então a redissolução do $\mathrm{Si}$ particulado, explicando os valores elevados de Si dissolvido no ERD mesmo com salinidade elevada.

\section{CONSIDERAÇÕES FINAIS}

Os estuários dos rios Tavares e Defuntos são dois sistemas de escalas bastante reduzidas inseridos em um cenário grandemente influenciado por diversas atividades antrópicas. Ambos os sistemas deságuam no Saco dos Limões, onde foi realizado nos últimos anos um aterro hidráulico em toda a sua porção interna. Estes sistemas estuarinos, apesar de estarem distantes apenas algumas centenas de metros, apresentaram grandes diferenças nas variações dos parâmetros monitorados.

O principal agente regulador e determinante da hidrodinâmica, em ambos os estuários, foi a maré astronômica semi-diurna, com período de 12:25 horas. Contudo, também foi constatado que seiches formados por diferentes modos de oscilação natural no sistema de baías também apresentam uma forte componente sobre a hidrodinâmica, sendo notavelmente observados no sinal de correntes longitudinal do ERT. A análise espectral sobre os dados de nível de água indicaram que estes seiches apresentam períodos de 1 até 2 horas.

Também em função de se localizarem em uma região com um extenso plano intermareal defronte, estes estuários estão sujeitos a processos hidrodinâmicos, sedimentológicos e biogeoquímicos que ali ocorrem. O plano intermareal representaria o elo entre a baía e os estuários, onde os processos de produção de matéria orgânica seriam particularmente importantes. Em função da pouca profundidade, alta concentração de nutrientes e relativa baixa turbidez, o plano intermareal constitui um local ideal para os produtores primários. Os estuários, principalmente o ERT, exportam nutrientes para a região do plano intermareal. Estes nutrientes são utilizados principalmente na maré baixa, e com a enchente parte desta água parcialmente misturada com a água da baía retorna aos estuários seguida por esta última, provocando a diminuição dos nutrientes e parâmetros relacionados. Estes processos são mais evidentes no ERD, em função de sua drenagem reduzida e sua comunicação restrita com a baía. Os resultados também mostram que a água de enchente no ERD é influenciada pela pluma do ERT, o que sugere a existência de um padrão de correntes horário no interior do Saco dos Limões, com transporte residual de leste para oeste na região da reserva.

\section{AGRADECIMENTOS}

Este trabalho foi realizado com o suporte financeiro do Departamento de Estradas e Rodagem - Santa Catarina (DER-SC), dentro do programa de Monitoramento Ambiental na 
Área de Abrangência das Obras da Via Expressa SC-Sul, Florianópolis, SC. Agradecemos ao Sr. Valdenir Manoel Inês pelo apoio logístico durante as campanhas de coleta e ao late Clube Veleiros da llha, por gentilmente nos ceder suas dependências para a instalação do marégrafo e realização do processamento das amostras.

\section{REFERENCIAS BIBLIOGRÁFICAS}

Braga, E.S.; Bonetti, C.V.D.H.; Burone, L. \& J. Bonetti Filho. 2000. Eutrophication and Bacterial Pollution Caused by Industrial and Domestic Wastes at the Baixada Santista Estuarine System - Brazil. Marine Pollution Bulletin, 40(2):165-173.

Cameron, W.M. \& D.W. Pritchard. 1963. Estuaries. In: Hill, M.N. ed. The sea, Vol. 2. New York, John Wiley \& Sons, pp.306324.

Chester, R. 1990. Marine Geochemistry. Unwin Hyman.London..

Fairbridge, R.W. 1980 The estuary: its definition and geodynamic cycle. In: Olausson, E. \& Cato, I. [Eds.] Chemistry and biogeochemistry of estuaries. New York, John Wiley and Sons, pp.1-35.

Pereira Filho, J.; Schettini, C.A.F.; Rörig, L.R.. \& E. Siegle. 2001. Intratidal variation and net transport of dissolved inorganic nutrients, POC and chlorophyll-a in the Camboriú River Estuary, Brazil. Estuarine, Coastal and Shelf Science, 53:249-257.

Perillo, G.M.E. 1995. Definitions and gemorphologic classifications of estuaries. In: Perillo, G.M.E. [Ed.] Geomorphology and sedimentology of estuaries. New York, Elsevier, pp. 17-47.

Pugh, D.T. 1987. Tides, surges and mean sealevel. New York, John Wiley and Sons, $472 p$.

Schettini, C.A.F.; Carvalho, J.L.B. \& P. Jabor. 1996. Comparative hydrology and suspended matter distribution of four estuaries in Santa Catarina State - Southern
Brazil. Workshop on Comparative Studies of Temperate Coast Estuaries, Bahía Blanca, Argentina, Proceedings... UNS/ IADO/NSF/IAI, pp29-32.

Schettini, C.A.F. \& C.A. D'Aquino. 1998. Efeitos da salinidade na medição de sedimentos em suspensão por turbidímetros de retro espalhamento. In: Encontro de Engenharia de Sedimentos, 3, Belo Horizonte, Anais... ABRH, pp.305-311.

Schubel, J.R. \& V.S. Kennedy. 1984. The estuary as a filter: an introduction. In: Kennedy, V.S. [Ed.] The estuary as a filter. New York, Academic Press, pp.1-11.

Spencer, C.P. 1975. The Micronutrient elements. In: Priley, J. P. \& Skirrow, G.[Ed.]. Chemical Oceanography. Vol.3. New York 2nd .Academic Press, pp.245-299.

Strickland, J.D. \& T.R. Parsons. 1972. A Pratical Handbook of Seawater Analysis. Fisheries Research. Board of Canada Bulletin. 2nd Edition, pp.1-311. 